\title{
Integrating Corporate Competence with Real Cases into Higher Education Curriculum
}

\author{
http://dx.doi.org/10.3991/ijac.v7i2.3597 \\ Hong $\mathrm{Wu}$ \\ Østfold University College, Fredrikstad, Norway
}

\begin{abstract}
Industrial competence and real business cases can be great attributes to higher education curriculum. For engineering higher education, there is a need for these attributes, not only to enrich the curriculum, but also to reduce the gap between theories and practices. An innovative teaching approach is integrating these attributes into off campus industrial lectures conducted during company visits. This paper writes about implementing and learning experiences on such off campus teaching approach at Ostfold University College (HIOF). The paper documented students' surveys, feedback and reflections on their off campus industrial lectures, and stated great learning outcomes through real company cases.
\end{abstract}

Index Terms-off campus teaching approach, corporate competence, company case.

\section{INTRODUCTION}

For professional higher education there is always a need for good matching between theoretic and practical approaches. This is also a challengeable task for many education institutions due to different natures of both approaches. The theoretic approach is by nature, required and based summarized research outcomes with general knowledge for universal cases. On the other hand, good understanding of the general knowledge needs to apply into specific cases, often with modification and practical implementations. University college graduated students need to learn how theories are used in the practical working life. The industries need what they called Day-One engineers, whose can quickly become company contributors among the first days.

Teaching and learning in higher education face nowadays the similar challenges as other industries and businesses, namely the requirement of efficiency and service demanding. The quality requirement for teaching is increasing and so does customer's, thus student's demanding. It is an essential task for every professor to motivating students' engagement in a subject, about all reading curriculum and learning updated knowledge.

UNESCO defined four pillars of learning: Learning to know, Learning to do, Learning to be and Learning to live together [4]. The future education curriculum is therefore not one of these, but combined all of four as a sustainable and complex whole. Other studies found the benefits of bring the real life experience into teaching [3], combining work and study [5], stating the need of various styles on lessons for learning outcomes [1] and practicing internal ship placement at the industries [2].

Teaching in higher education is no longer merely emphasized on researching and exploring knowledge solely, but also emphasized on integrating with other actors, disseminating and educational outcomes. With this new emphasis, the idea of moving classroom out off campus, combining and teaching higher education curriculum by integrating corporate competence might provide a new and beneficial teaching option for higher education. This idea has been tried out throughout one study case carried by Østfold University College (HIOF) incorporated with regional business community and industrial commerce.

\section{THE INITIATION OF INTEGRATING CORPORATE COMPTENCE PROJECT}

Østfold is a tiny county in southeast of Oslo, capital of Norway, with a good infrastructure and well-built logistic access to European continent, results a nature fundament for business activities. There are over 20000 registered business companies mainly small and medium size enterprises (SME) in the county with large variety types of business and significant production outputs. This business character contributes positively to integrating of corporate competence for higher education curriculum. A good network links the university college and business communities and there is a short distance between them both in personal and in geographic aspects.

The regional business community, represented by the Confederation of Norwegian Enterprise (NHO) is a good supporter for this integrating corporate competence into engineering curriculum. They assist extensively the university college for establishing contact network and coordinating the education needs with corporate competence throughout selected companies.

Other networks including few research programs are also contributing for bridging the university college and few participating companies. The general responses from local industries are positive and overwhelming. There are two particularly relevant industrial sectors noticed, one is packaging industries and the other is plastic industries involved into research networks. Both represented an uprising trend for regional industrial development, so integrating corporate competence is also updated.

Both mentioned industries are all highly production focused with a great variety of products and this character matches perfectly our educational need, thus learning by industrial cases. Some products are easy and simple to illustrate as packing industries where products are normally confined by sizes, colors, features or dimensions, while others require more detailed and basic knowledge, as plastic industries where most products composited by variety of different chemical or material components, and their production processes are rather complex. However, the combination of packing industry and plastic industry will 
match perfectly for the need of a great variety of different industrial cases for teaching purpose.

\section{THE PILOT PROJECT AND SELECTED COURSES}

HIOF initiated a pilot project in 2009 for realizing this practice. Over 30 regional companies were asked for joining this pilot project and contributing the competence to higher education curriculum. Half numbers made commitment to the pilot project and appointed their key coordinators to collaborate with the university college. Most companies valued highly and appreciate truly their roles as university partners. Many company managers have high real working life competence and industrial expertise, matching perfectly for off campus teaching for selected university courses, such as "Product development", "Industrial marketing", "Production techniques", etc. These majors are systematization and theorization of cases and tasks of real life tasks or projects from industry.

Most companies appraised highly the preparing work for their lectures, not only fostering on presenting and promoting their firms, but also more academic and detailed knowledge for teaching. Many companies appreciated afterwards this academic approach, saying they have been also benefited for own needs, so that they are able to summarize and reflect their daily tasks systematically on an academic and different level.

\section{THE ORGANIZING OF COMPANY LECTURES}

These off campus company lectures are organized as a part of ordinary teaching curriculum. One sample is a HIOF course in "Product development", one of few initiatives during the pilot project. Figure 1 shows the organization flow chart of this course content by topics and activities. The course is 10 ECTS (European Credit Transfer System), roughly equal to 100 hours lecturing. The course is teaching students basic knowledge and skills in product design methods. The lecture activities include, by time order and circa hours, 10 hours for self-selected cases for student projects (motivation), 20 hours of theoretic lectures for methods (basic knowledge), 15 hours selfselected cases for group project (cooperation skills), 10 hours, equally 2-3 visits in companies with industrial lectures (see real life cases), 10 hours for writing individual reflections (self-learning), 15 hours conducting real life cases for appointed companies in groups (practicing real skills), following another 10 hours new company visits with industrial lectures (new cases), then 10 hours preparing or coaching for final project presentations.

The company lectures represent 20 percent of total lecture time budget and these lectures are scheduled at middle and end of teaching period. This was carefully scheduled since the students must learn basic knowledge of product design before they see company cases. It is also beneficial to schedule reflection and let the students try out real cases before they visit another companies and learn more real cases to enrich their own learning results.

A typical company lecture is combined 1-2 thematic lecture in one hour for visiting students. The thematic topics are usually selected from the company's daily business tasks, for instance, showing a case product, designed or developed by the company, presenting the history and working processes of the case, summarizing why this product was needed and how the company seeks the po-

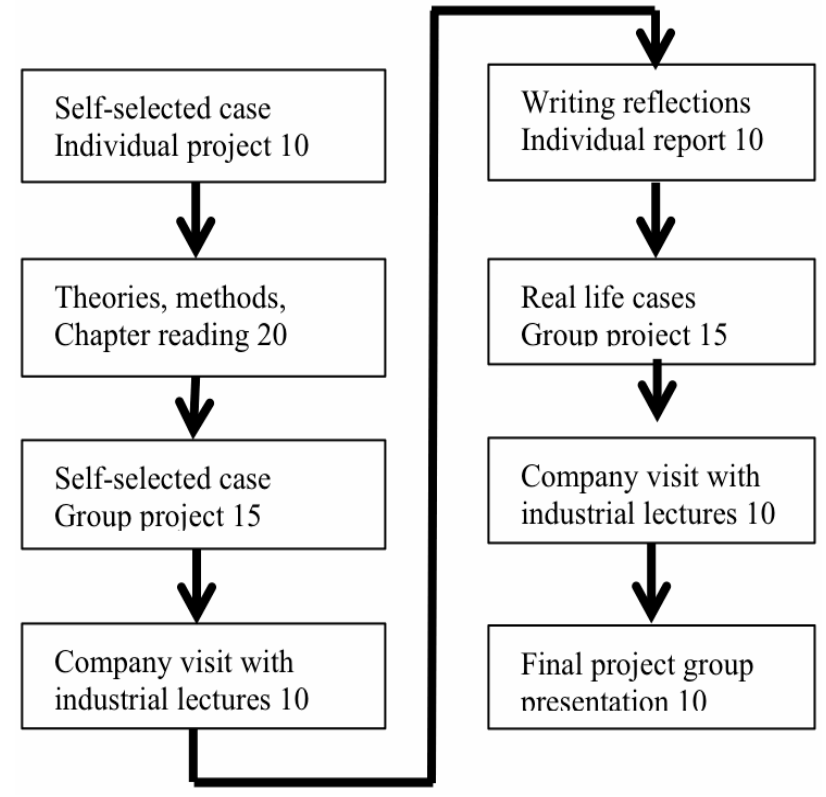

Figure 1. The organization flow chart of HIOF course Product Development in hourly lecture relevant activities

tential market or collaborates with clients for product specifications, explaining how the product design must be coped with production framework. In this way, the product development process with every step is well illustrated as from a holistic aspect.

From a learning process point of view, this actually is a case study with local context. For many students, cases in prestige textbooks are selected from other countries than Norway, most likely USA or UK, and these cases seem to be unfamiliar and lack of local context for Norwegian students and hard to learn. Company lectures contribute the cases with local context bringing a great advantage compared with cases from textbooks. It is easier to learn company cases since everything is in local.

One essential part of learning session is a plant tour combined with company lecture. The plant tour is meant for visualizing thematic topics, explaining every technical detail much better than any sketch compared with a textbook. Figure 2 depictures a plant tour starting in a product showroom so the students can see and touch different product samples, in this particular company visit, different packages. The tour is also taking students into the production plant showed in figure 3 and the tour is showing the students how packages are produced in the reality. Though the company lecture topic was product development, the students need to learn the whole process including production plant to understand inter-dependent steps of the whole product development process.

A long term positive effect of company lectures might be bridging the gap between theories and practices. Nowadays many students are directly from high school with no working experience. Therefore, company lectures are good options to be getting familiar with real working life, and learning the industries. Most students appreciate these options and left positive feedback for the visits. There is however variety among learning outcomes when checking how students cope methodology issues in the plant comparing in the textbook. 
PAPER

INTEGRATING CORPorATE COMPETENCE With REAL CASES INTO HighER EdUCATION CURRICULUM

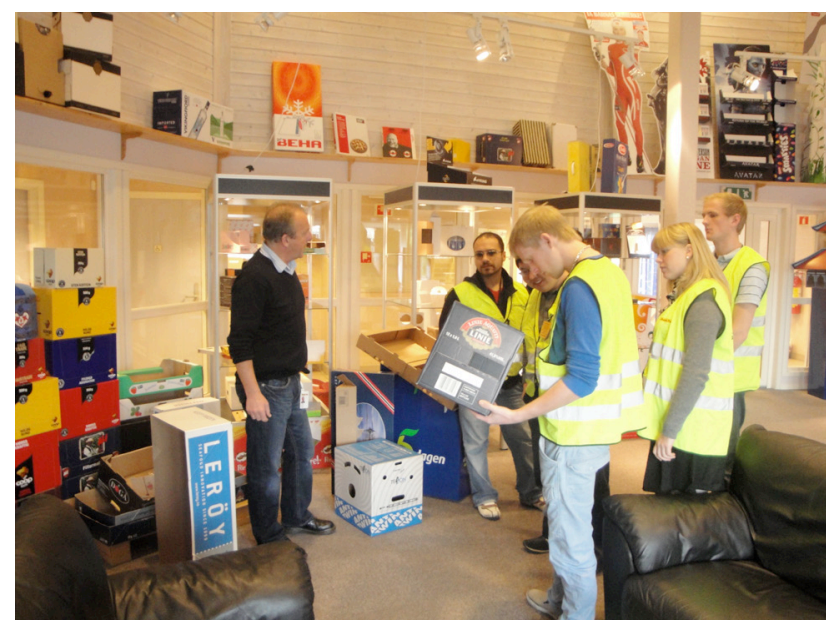

Figure 2. A plant tour starting at a product showroom so students can see and touch different product samples

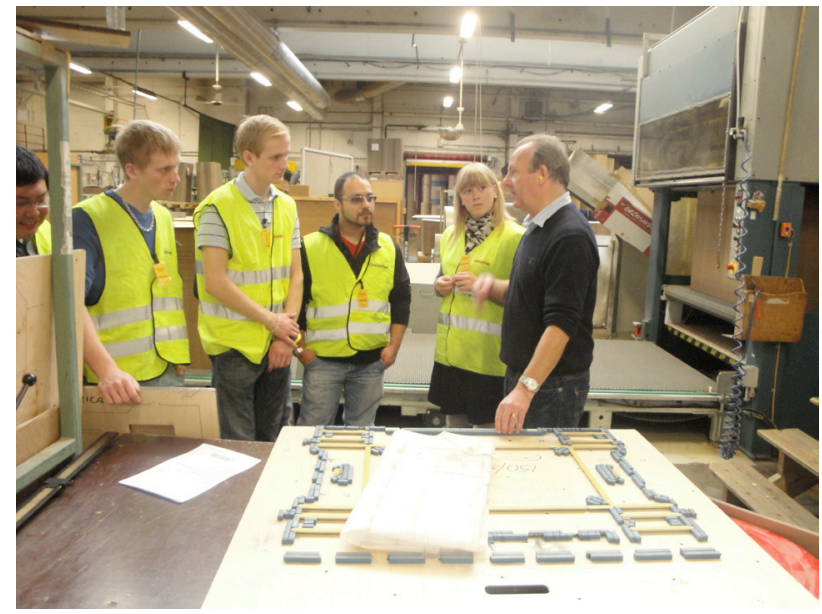

Figure 3. A plant tour in production plant to learn the product development as a whole process with manufacturing

\section{THE PROJECT'S EDUCATIONAL DEVELOPMENT, LEARNING AND ACADEMIC OUTCOMES}

One open and challengeable question often asked by that many higher education lecturers, is how to motivate college students to study their majors enthusiastically and guide their learning interests towards teaching materials. There is usually a barrier between theories and practices and demonstrating theories through case studies or practical examples is a common teaching approach. There is also a need in exemplifying "standard" curriculum to local context or with own interpretations. Currently many engineering higher education prefer to use English textbooks as learning sources. Still, this might bring some challenges or difficulties for none-English speaking students to read and understand learning materials efficiently. The current HIOF pilot project for company lecture has a great advantage to lecture students many specific and practical business cases and samples, especially cases generated from local businesses where students are able to recognize both the companies and their products.

A student evaluation of the course is a best barometer indicating direct responses on lecture outcomes. One standard question in qualitative surveys is asking students state three most positive elements or activities throughout the course "Product Development". They can state any
TABLE I.

MENTIONED FREQUENCIES ON COMPANY LECTURE BY STUDENT SURVEYS AMONG 3 BEST COURSE ACTIVITIES

\begin{tabular}{|l|l|c|}
\hline $\begin{array}{l}\text { When survey under- } \\
\text { taken }\end{array}$ & $\begin{array}{l}\text { Number re- } \\
\text { spondents }\end{array}$ & $\begin{array}{c}\text { Frequencies company } \\
\text { lecture mentioned }\end{array}$ \\
\hline 2013 Fall & $\mathrm{N}=6$ & 1 \\
\hline 2013 May & $\mathrm{N}=15$ & 3 \\
\hline 2012 Fall & $\mathrm{N}=19$ & 1 \\
\hline 2012 May & $\mathrm{N}=7$ & 1 \\
\hline 2012 March & $\mathrm{N}=4$ & 0 \\
\hline 2011 Fall & $\mathrm{N}=15$ & 0 \\
\hline 2010 Fall & $\mathrm{N}=12$ & 1 \\
\hline 2013 Fall & $\mathrm{N}=6$ & 1 \\
\hline
\end{tabular}

elements they prefer so the variety in different elements or activities can be great. However, the term "company lecture" activity was mentioned as a positive element almost in every surveys showed in table I, except surveys in 2012 March and 2011 fall. This was probably because both surveys designed own separate questions asking for students' feedback on their company lectures, so the issue was covered by own separate questions and answers.

Though these surveys might not provide sufficient statistical data for a significant quantitative analysis, the student comments, their reflection notes, and direct class feedback during the classroom lectures all indicate they prefer varying forms of the lectures and presentations. A best learning option is a combination of company visits, theme based industrial lectures, as well as self-organized study, supplemented students own case projects.

\section{THE REFLECTIONS ON COMPANY LECTURES}

The course evaluations by students also confirmed the positive learning outcomes of company lectures. The few narrative quotations are extracted from the students' evaluation surveys and their reflection notes. Some appraised the motivation and variation elements as the quotation below stated:

I think it's great for company visits. It's exciting and it's fine with little hours where we do not just sit and read. It's very interesting to see how the theory works in the real workplace.

The company visit was valued by this student as the best combination of theory and practice, so the student can see theory works in practice, and the further theory learning is even more motivated. The lecture form was also varied so students not just sit and read, but also see and ask so the variation is great for the leaning process.

Other students might experience the company lectures as understanding of a holistic working process, as one of students wrote about:

Very interesting company visits, it has given me greater insight into the process. This company was probably the company that managed to put the theoretical process more in place. It may be that they work more administratively (marketing/customers) and are more focused on this part than a manufacturing company, which is more focused on the work being done in production.

The company mentioned above was a typical product design company focused more on customers and market needs, though the company is also responsible for product delivery, but throughout a contracted and outsourced pro- 
duction subcontractor. Throughout this company visit, the students have learned basic knowledge about the company's business process strategy by contracting away a heavy part but focus on the best competence in design.

The company lectures are organized separate periods, showed in figure 1 . The first period plans 2-3 company visits in fall semester and another 2-3 company visits in spring semester. This was scheduled in a thought of learning curve aspect, that the students might need time to appreciate and understand company lectures after first period, the learning outcomes will be even better for second period.

The students have participated in the company visits combined with business lectures that showing how theories will work in practice through real business cases. The students can see and learn about the companies and the products and working processes in these companies, observed how things worked in reality, so they are motived to learn more knowledge and perhaps being engaged more professional commitment later study or career stages.

There are students whom appreciated the company visits with lectures and consider such industrial lectures as increasing level and interests of the study. They express the wish and demand on similar arrangements in a later stage:

Company visits and industrial case presentation is very interesting. This means that we'll see what we learn about put into practice. This raises the level of and interest in the subject very much. It had been even better if we could have arranged a site visit in the course of six months.

As the students obtained more knowledge from their company lectures, they are able to reflect and compare with different companies and cases. They have learned the different real business cases in details or procedures, so they are even obsessed by what they are leaning. As a quotation below indicated a student stated what were most interests during the visit, but also what wished to be done a better planning for company lectures in future:

I think it is very useful, especially visits to this company. The fact that they tell about their 3 of 9 product development is intriguing. It is also interesting to know how the procedures work in different businesses. To do this better, it should be time for preparation in advance. Get a brief glance of what your business is doing and what ways they are working on (view it possible). So we are more prepared for the visit and can be even more involved and possibly the questions or indeed understand more.

A great advantage on the mentioned company visits is that they all are located very close to the university college geographically, and their products are consumer based, easily recognizable for common people and some are well known by local people. For instance, a packaging industry shows their products of cardboard packages for frozen fish, juice or bike helmet, etc. all recognizable for average people. This makes this business lecture very accessible, understandable and touchable for the students, what we usually called down to the bottom lines. All these elements contribute positively to involvement of student discussions on pedagogical and professional items. These business lectures also contribute positively learning process and this has been stated by students' learning reflections as one of these quoted below:

Of the things I think is great about lectures / lessons, I particularly like to highlight guest lectures and company visits we have been, they have helped me very much and been fun, interesting and educational. This has resulted in not only have we learned various views on product development, but that we can actively take this with us in the companies we work in, compared to what I first thought about the subject I have now seen that the product is more than just the idea, it is the process involved.

The student has also reflected own learning process and came up with a good understanding of a product development process is not just an idea, but a process involved. This experience and appreciation for company lectures is accounted as an important part of understanding of the theories and specifications, which again, makes the student well motivated to learn more.

In a textbook, the topic might be divided into different chapters, so each chapter will structure the content, such as design, concept, manufacturing, market and brandy management, sales and client relations, etc. In a company lecture, these topics can be easily combined and presented through one or two real cases, as the quotation from one of students wrote comments after visiting a candy and nuts company:

Company visit we had was Company B (candy and nuts producer). They are the manufacturer of candy and nuts, and it has else few more brand products its portfolio. Here we had a lecturer who talked about how to makes product development to keep pace with the market. I understood it so that the industry as they are, it is vital to constantly introduce new products or further development of existing products to maintain its market share. We also received a tour of the production of the factory. It was instructive to see how the process worked from the nuts as raw material came to the factory, and then were packaged in bags for sale.

The reflection note indicated this particular company lecture has contributed the students not only generally basic knowledge and product specifications, but also an overall picture of how the business process worked and developed in a real world, including market, brand, manufacturing and packaging. This is a confirmation on a good pedagogical approach that any other theoretic textbooks might have difficulty to match in disseminating content for students.

Overall, the summary of student direct feedback and learning reflections confirmed positive learning outcomes of integrating corporate competence into higher education curriculum. The positive learning outcomes are many as the students own statements, lifting motivation, holistic view, engagement, understanding details and the whole process complexity.

\section{THE OPEN AND DIGITAL LEARNING RESOURCES}

This pilot project has few other missions to practice as well, and one is crating open learning sources and unlocking lecture materials available for public access. This practice was encouraged and required according to Open Education Resources (OER) principle [6], widely applied through MIT open courseware (OCW) practice [7]. The practice has however experienced some real challenges, for instance, finding a good balance between displaying most detailed knowledge from a real business case in order to provide best lecture materials for educational purpose versus intellectual properties (IP), or simply retention or protection of confidential business information in a 
highly business competitive situation. Most companies are normally reluctant to disclose their technical details in concerning other competitors. At the same time, more and more companies realized a fact that public education might be the best way for promoting their business or solutions for the society.

For best balancing, the project has experienced mutual involvement is a must for both sides, that the university college teachers need to learn real business cases first to pick up the best available for education purposes. The company partners need to review their real business cases in details and disclose the most relevant one for public.

During the pilot project, all participating companies are encouraged to contribute their lecture materials open online for public access. Half of the companies have executed this practice and approved permission to publish lecture notes openly throughout the internet. It has been a very positive experience in collaboration with companies for publishing their lecture materials open online, and the company's positive attitudes can be noticed even more positive and open than many academic colleagues when discussing the lecture materials published open online.

The pilot project has another intention to establish an industrial and business network for the university college in knowledge updating. The idea was collecting and updating fresh knowledge generating by industrial front lines. This knowledge base functions also as a database for all contributions and lecture materials given by the companies, so the university college is a mutual and neutral platform for many business partners. This goal was achieved to some extend as throughout this pilot project, a number of companies are becoming the university college's partners and they meet each other during the business platform arranged by the university college, for instance, through business breakfast meeting.

\section{THE PROJECT KNOWLEDGE DEVELOPMENT}

The summary of this project on the use experiences show the positive knowledge development in collaboration with industrial partners, specifically through integrating topic based lectures and using industrial competence into college teaching curriculums. The project is a dynamic process that involved many industrial partners within network which can be rewarding for different partners and directions. As a result, a teaching curriculum is updated by fresh knowledge and contributions from industrial partners. The students learned and renewed the updated knowledge by industrial competition in front lines.

On the other hand, there is also a positive element for invited and involved businesses partners whom work or refresh their daily tasks or their products in academic and systematical approaches, which again benefit their product and case presentations for guest lectures. The major beneficial group will be college students whom obtaining specific, useful and interesting cases and theme-based teaching curriculum directly picked up from real industrial cases.

The region's geographic location made a nature competitive advantage for doing this teaching approach. Østfold is traditionally an industrial region of Norway, including many business companies with their own expertise in a great variety of disciplines. One of the great advantages is relatively fresh and quick updating knowledge and technology in these business companies, which again, can contribute as an important supplement to college education. The university college takes advantage on this, and legislate it into the strategy plan, defining this approach as an important task in knowledge development and cooperation with regional businesses.

There are however challenges during the operative actions. Involving in partners often have their own daily tasks, priorities, procedures, not least, a working language, and thus requires a considerable efforts on tailored design for detailed teaching hours and particular company visit.

The overall experiences on this issue are getting student companies visits are often a simple matter and easily accomplished, but getting student company visits with theme-based instruction in business with a specific case from company required more often much more. It required the business partners and companies must think "academically", when they prepared for the guest lectures and focusing on explanations of theoretic approaches, such as questions of "how and why we do so" than only "what we." It requires considerably balancing efforts in disclosing detail knowledge versus retained corporate confidential information on industrial lecture content and materials, and even more demanding, publishing the lecture materials in open internet available for everyone according to OER principle and MIT OCW practices.

\section{THE PROJECT CONCLUSIONS AND OUTCOMES}

During this pilot project, off campus based company lecture was introduced as a supplement teaching means and experimented throughout few selected HIOF courses. The project main stockholders are the university teachers and students whom wish to improve teaching approaches to achieve better combination of theories and practices. The contributive actors are company partners with industrial lecturers contributing their real business cases, their life experiences and competences, as an integrated part of teaching curriculum.

The overall objectives was reducing the gap between theories and practices, furthermore, focusing on learning outcomes and better understanding of how methodologies applied in a real world. Throughout the experiences and knowledge collecting, the pilot project might come up with following conclusions:

- There is a need and wish from students for seeing more practice based teaching approaches.

- The industries and society are also looking for candidates with practical and real skills in addition of theoretic analysis skills.

- Off campus based company lecture is a motivated and beneficial teaching option for college students.

- The company lecture materials are good supplement and interpretations for theoretic methods in the textbook.

- The students are better motivated and engaged in the subject during and after company lectures.

- The university and industrial companies need to collaborate together and joint develop company lecture material best available for the students.

- A SME (Small and Medium Size Enterprises) environment contributes positively a great variety in company lecture topics and real cases, again benefits off campus lectures greatly. 
PAPER

- University teachers need to be leaners, to speak and understand industrial languages and have good dialogs with industrial partners in order to achieve this collaboration.

- Once the collaboration succeed, the beneficial parts will be shared by all stockholders, as the students will obtain better learning outcomes, the university will access supplement lecture materials and the companies will present their competence and real experiences in a systematic and academic way.

The higher education curriculum needs to be updated and debated continually in order to keep the learning content fresh. There is an academic debate on balancing of knowledge acquisition versus knowledge production as requiring work loading for college students and it seems to be hard to get everyone being agree [8]. The alternative off campus company lecture might be an interesting and beneficial contribution to this debate and to the future education content.

\section{ACKNOWLEDGMENT}

This pilot project is a part of a flexible and open teaching project entitled "Industrial and practice integrated study module in bachelor education of innovation and project management" and funded by Norway Opening University (NOU). The pilot project was undertaken in collaboration with the Confederation of Norwegian Enterprise (NHO), Østfold Regional Office. The author would like to thank for NOU and NHO supports and contributions during this project.

\section{REFERENCES}

[1] E-B, Dylan, "Integrated Curricular Approaches in Reaching Adult Students," Adult Learning. Vol. 24 Issue 3, p128-130. 3p. Aug2013.
[2] R. Garcia and J. Puig "A Model for Improving the Quality of Student Internship Placements in Engineering Degrees," in International Journal of Advanced Corporate Learning. Vol 4, No 1, 2011, pp. 4-11.

[3] G. Pasman and I. Mulder "Bringing the Everyday Life into Engineering Education," in International Journal of Advanced Corporate Learning. Vol 4, No 1, 2011, pp. 25-31.

[4] UNESCO Mission: "The four pillars of education for the 21st Century."

http://www.unesco.org/new/en/education/networks/globalnetworks/aspnet/about-us/mission/

[5] K. C. Lim, S. Low, S. Attallah, P. Cheang and E. LaBoone, "A Model for Teaching, Assessment and Learning in Engineering Education for Working Adults," in International Journal of Advanced Corporate Learning. Vol 5, No 4, 2012, pp. 16-21.

[6] OER "Open Educational Resources," from Wikipedia, the free encyclopedia. http://en.wikipedia.org/wiki/Open_educational_resources

[7] MIT OCW "MIT Open Course Ware," from Wikipedia, the free encyclopedia. http://en.wikipedia.org/wiki/MIT OpenCourseWare

[8] C. Manathunga, M. Kiley, D. Boud and R. Cantwell "From knowledge acquisition to knowledge production: issues with Australian honours curricula," in Teaching in Higher Education. Vol. 17 Issue 2, Apr2012, p139-151. http://dx.doi.org/10.1080/ 13562517.2011 .590981

\section{AUTHORS}

Hong Wu is with Østfold University College, Faculty of Engineering, Kobberslagerstredet 5, Fredrikstad, N1761, Norway (e-mail: hong.wu@ hiof.no).

Submitted 25 February 2014. Published as re-submitted by the author 08 June 2014. 